\title{
Leziunile renale multiple duc la deces în chirurgia cardiacă chiar și cu hemodiafiltrare precoce
}

\author{
Mihaela Bizubac ${ }^{1}$, Cătălin Cîrstoveanu1,2, Cristina Filip ${ }^{3}$, Alin Nicolescu ${ }^{3}$, \\ Ileana Bărăscu', Ruxandra Chircă', Alina Gaiduchevici', Doina Anca Pleșca ${ }^{2,4}$ \\ ${ }^{1}$ Terapie Intensivă nou-născuți, Spitalul Clinic de Urgenţă pentru Copii „M.S. Curie“, \\ București, România \\ 2Universitatea de Medicină şi Farmacie „Carol Davila“, București, România \\ ${ }^{3}$ Cardiologie Pediatrică, Spitalul Clinic de Urgenţă pentru Copii „M.S. Curie“, București, România \\ ${ }^{4}$ Spitalul Clinic de Copii „Dr. Victor Gomoiu“, București, România
}

\begin{abstract}
REZUMAT
Prezentăm cazul unui nou-născut diagnosticat cu suferintă perinatală și injurie renală secundară, transpoziție de vase mari și debit sistemic scăzut, tratat cu prostaglandină, atrioseptostomie, urmate de operația de switch arterial. Postoperator, pacientul este oliguric și necesită hemodiafiltrare pentru 12 zile, după care funcția renală este restabilită. În evoluție, apare bloc atrioventricular (BAV) grad III, urmat de implantare de stimulator cardiac permanent, dar o altă complicație postoperatorie - chilotorax - duce la oprirea stimulării electrice, urmată de disfuncție cardiacă severă și, consecutiv, injurie renală recurentă și anurie. Se reinstituie hemodiafiltrarea pentru încă 7 zile, fără recuperarea funcției renale. Asfixia perinatală, malformația cardiacă cu debit sistemic scăzut, prostaglandina, atrioseptostomia, circulația extracoroporeală, tulburările de ritm, chilotoraxul, sepsisul, stopul cardiac sunt factori intricaţi care aduc injurie renală importantă. Asocierea lor scade major șansele de supraviețuire chiar dacă pacientul beneficiază de tratament suportiv și hemodiafiltrare precoce.
\end{abstract}

Cuvinte cheie: hemodiafiltrare, insuficiență renală acută, nou-născut, transpoziţie de vase mari, malfuncţie stimulator cardiac permanent, chilotorax

\section{INTRODUCERE}

Insuficiență renală acută (IRA) la nou-născut continuă să fie o cauză importantă de morbiditate și mortalitate, $25-30 \%$ dintre nou-născuții din TINN (Terapie Intensivă nou-născuți) având afectare renală (1). Deși nu este un consens în ceea ce privește diagnosticul, tot mai multe clinici utilizează criteriile KDIGO (Kidney Disease Improving Global Outcomes) modificate pentru nou-născut (n-KDIGO), care au la bază scăderea diurezei sub $1 \mathrm{ml} / \mathrm{kg} /$ oră și creșterea creatininei serice cu mai mult de $0,3 \mathrm{mg} / \mathrm{dl}$ sau peste $50 \%$ din valoarea anterioară (2). Dificultătile sunt legate de faptul că, în primele 72 ore, nivelul creatininei poate fi crescut, în concordanţă cu nivelul seric al mamei, iar cele mai multe injurii renale la nou-născut, în fazele incipiente, sunt nonoligurice (3). Acest lucru se datorează faptului că nou-născuții au o imaturitate a funcției tubulare renale, cu o capacitate limitată de concentrare a urinei și un procent mare de apă în compoziţia corpului (4). În $85 \%$ dintre cazuri, IRA neonatală este de etiologie prerenală, putând deveni intrinsecă în contextul prelungirii injuriei renale. Deshidratarea, asfixia perinatală, malformațiile renale, trombozele vaselor renale, sepsisul și chirurgia cardiovasculară sunt printre cele mai frecvente cauze de afectare renală la nou-născut (5), dar există şi cauze mai puțin frecvente, precum bolile metabolice, tulburările de ritm sau chilotoraxul. 


\section{PREZENTAREA CAZULUI}

Prezentăm cazul unui nou-născut de sex feminin, la temen, extras prin operație cezariană de urgență pentru suferinţă fetală acută, GN = 3.000 g, SA 6, care prezintă postnatal convulsii și modificări cerebrale specifice encefalopatiei hipoxic-ischemice. Este diagnosticat imediat postnatal cu transpoziție de vase mari, ce asociază defect septal ventricular muscular înalt și minim foramen ovale. Se administrează prostaglandină şi se practică septostomie atrială Raskind pe vena ombilicală. Strict în timpul procedurii, s-au înregistrat tulburări de ritm cardiac remise spontan, fără dezechilibre hemodinamice, urmate de îmbunătățirea $\mathrm{SpO} 2$ de la $78 \%$ la $85 \%$ postseptostomie. În zilele următoare, prezintă edeme progresive şi scăderea diurezei (Figura 1), remise parţial după administrarea de diuretice (Furosemid) și Miofilin, iniţial în doze intermitente, apoi în perfuzie continuă până la doze maximale. Ecografia renală a exclus malformații ale aparatului renal sau tromboze vasculare la acest nivel. Intervenția chirurgicală are loc la 12 zile de viaţă și se practică switch arterial Jatene, ligatura canalului arterial, închidere defectului ventricular și a celui atrial postRashkind cu petice de pericard bovin. Timpul de circulaţie extracorporeală a fost de $283 \mathrm{~min}$ și timpul de clampare a aortei a fost de 145 min. Postoperator, se menţine cu stare generală gravă, edeme, necesită ventilație mecanică, $\mathrm{SpO} 2$ $=96-98 \%, \mathrm{AV}=150 \mathrm{bpm}$, cu stimulator cardiac temporar pe electrozi epicardici și suport inotropic (Adrenalină și Milrinonă). În orele următoare, prezintă tendinţă la hipotensiune, care necesită escaladarea dozelor de inotropice și suplimentarea cu Dopamină, Dobutamină și Noradenalină. Treptat, devine oligoanurică, cu edeme importante și valori crescute ale creatininei serice, ce necesită sternotomie decompresivă și montarea hemodiafiltrării CRRT-CVVHDF (continuous renal replacement therapy-continuous veno-venous hemodiafiltration).

S-a folosit ca abord vena femurală dreaptă, maşina Prismaflex Gambro HF 20 Set şi anticoagulare sistemică cu Heparină. Evoluția a fost favorabilă, cu reluarea diurezei, diminuarea edemelor şi scăderea valorilor creatininei (Figura 1). Sternul se închide după 5 zile, iar hemodiafiltrarea se întrerupe dupa 12 zile. Deoarece se menține BAV gradul III, la 18 zile postoperator, se montează simulator cardiac permanent prin implantarea electrodului la nivelul VD şi montarea aparatului anterior de mușchiul drept abdominal stâng. După 4 zile de la procedură, timp în care pacienta primeşte şi nutriție enterală, se constată chilotorax masiv bilateral. Se administrează Octreotide $10 \mu \mathrm{g} / \mathrm{kg} / \mathrm{h}$, se drenează ambele pleure, dar stimulatorul cardiac este in contact intim cu acest fluid (Figurile 2 şi 3), astfel că, la 14 zile de la implantare, se constată malfuncționarea stimulatorului permanent, cu bradicardie severă, hipotensiune arterială, desaturare şi stop cardiac. După resuscitare cardiopulmonară, se repornește stimulatorul cardiac temporar. Urmare a acestui eveniment, reapar oligoanuria şi edemele importante neresponsive la tratamentul diuretic si se reinițiază hemodiafiltrarea, menținută timp de 7 zile. S-a folosit același aparat de hemodiafiltrare, abordul a fost pe vena femurală stângă şi s-a utilizat aceeași tehnică folosită anterior. De această dată însă, se menține oligoanuria și, in ciuda tratamentului intensiv, funcția renală nu este recuperată (Figura 1). În a 41-a zi postoperator, prezintă stop cardiac ireversibil la manevre de resuscitare.

\section{DISCUȚII}

Injuria renală în cazul pacientei noastre s-a produs etapizat și au existat mai mulţi factori agravanți. Suferința fetală acută pentru care se practică operația

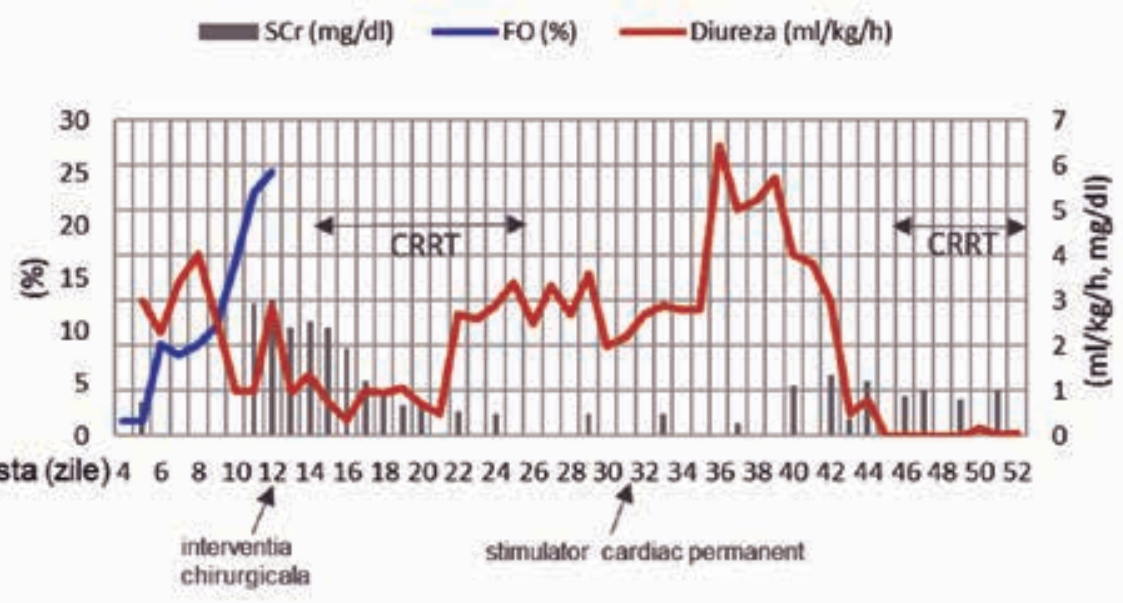

FIGURA 1. Evoluția zilnică a diurezei, creatininei serice şi încărcarea de fluide (fluid overload - FO) 


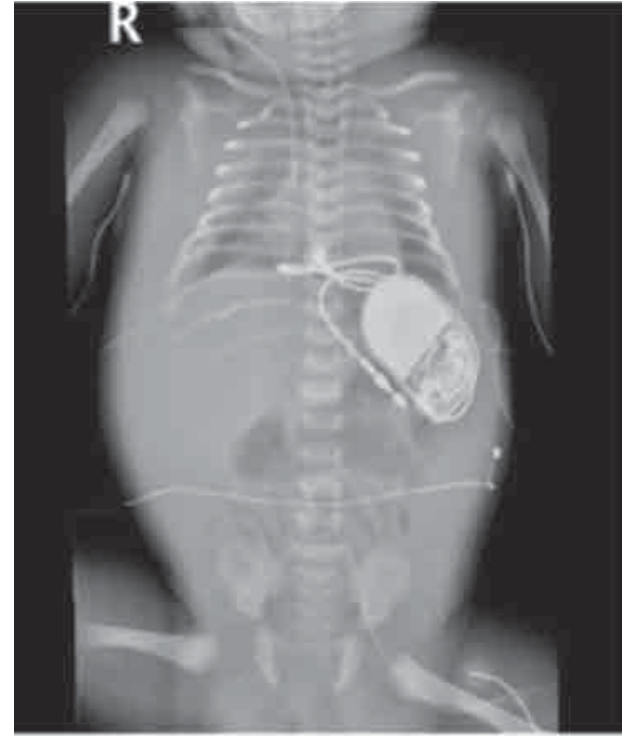

FIGURA 2. Radiografie toraco-abdominală. Colecție lichidiană în hemitoracele drept

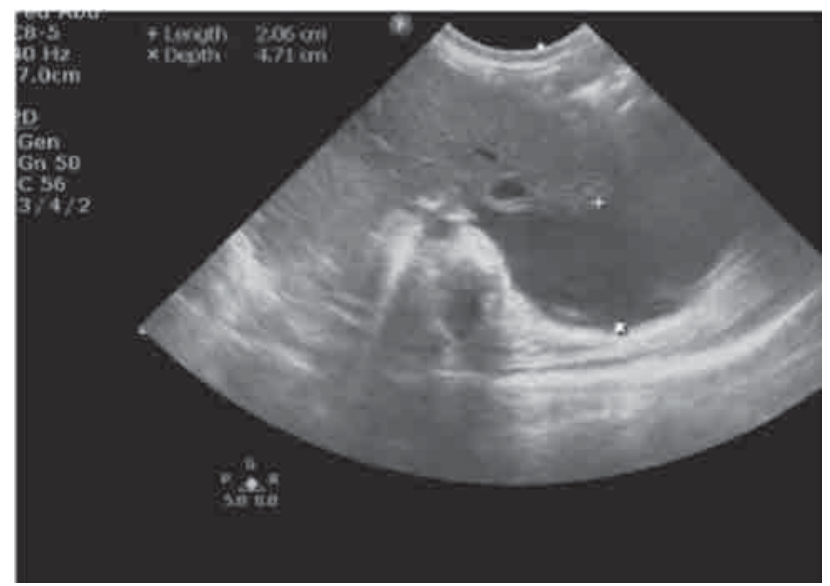

FIGURA 3. Ecografie torace. Colectie lichidiană în pleura stângă

cezariană se continuă postnatal cu encefalopatie hipoxic-ischemică și afectare renală posthipoxică. Incidența IRA la pacienții cu encefalopatie neonatală este de $41,6 \%$, aşa cum reiese din analiza AWAKEN (Assessment of Worldwide Acute Kidney Epidemiology in Neonates) (4). În primele momente după un eveniment hipoxic, are loc o redistribuire a fluxului sangvin pentru menținerea fluxului cerebral, cardiac și adrenal în detrimentul fluxului renal, gastrointestinal și perfuziei cutanate. Creşte eliberarea de adenozină, cu efecte vasoconstrictorii, ce determină reducerea filtrării glomerulare. Însuşi managementul asfixiei, prin restricția de fluide, nutriția parenterală și tratamentul antibiotic, a reprezentat un risc suplimentar pentru IRA (4). Chiar și malformația cardiacă prezentă, prin saturația scăzută a oxigenului şi valoarea scăzută a glucozei din aorta ascendentă, poate cauza afectare cerebrală perinatală (6). Funcția renală a fost restabilită în această fază medicamentos, cu ajutorul tratamentului diuretic.
Transpoziţia de vase mari asociază un debit sistemic scăzut şi scăderea perfuziei splanhnice, care se poate însă modifica în funcție de mixingul la nivelul canalului arterial sau septului interatrial (7). Ca indicator al perfuziei organelor, Klauwer și colab. recomandă urmărirea diurezei, preferabil în absența tratamentului diuretic (8).

Prostaglandina utilizată pentru menținerea deschisă a canalului arterial poate determina vasodilatație, care duce secundar la hipotensiune arterială (9) și IRA. Pacienta noastră a primit acest tratament din prima zi de viaţă.

Septostomia este o manevră ce poate determina IRA prin injurie cardiacă sau tulburări de ritm cardiac. În timpul procedurii, pacienta noastră a prezentat tulburări de ritm, însă fără impact hemodinamic. Harmer și colab. au efectuat un studiu în care au inclus 71 nou-născuți cu transpoziție de vase mari. 50,7\% dintre aceștia au dezvoltat IRA și la 11\% dintre ei a fost nevoie de CRRT. La 70\% dintre pacienţi, se practicase anterior atrioseptostomie cu balon, însă nu s-a constatat că atrioseptostomia se asociază cu creșterea nevoii de terapie de repleție renală (10).

Funcția renală s-a degradat însă semnificativ după intervenția chirurgicală, datele actuale aratând o incidență globală a IRA dupa chirurgia cardiacă la $30-40 \%$ dintre cazuri $(10,11)$, iar la nou-născuți intrun procent și mai mare, de până la 64\% (12), în funcție de complexitatea malformației. IRA apare în general în primele 3 zile postoperator (13), însă numai $1 \%$ dintre pacienții operaţi necesită terapie de repleție renală (10). În clinica noastră, în ultimii 6 ani, din totalul cazurilor care au necesitat CRRT (25 cazuri), $62 \%$ au fost postchirurgie cardiacă (14). Numeroase studii au arătat că afectarea renală după chirurgie cardiacă are atât factori de risc preoperatori (vârsta mică, afectare renală preexistentă, complexitatea malformaţiei sau ventilația mecanică preoperatorie) (12), cât şi factori de risc intraoperatori (hipotensiunea arterială, hemoglobina scăzută, chirurgia aortei, durata CEC şi timpul de clampare a aortei). Cauzele sunt multiple: injuria ischemie-reperfuzie, trauma mecanică a celulelor sangvine în circuitul de bypass, stresul oxidativ, edemul miocardic și deficitul de oxigenare. Reducerea presiunii arteriale medii și fluxul nonpulsatil în timpul CEC duc chiar la activarea apoptozei și moartea celulelor endoteliale și tubulare (15). O durată CEC mai mare de 180 min determină IRA la aproximativ $70 \%$ dintre pacienţi (11), iar un timp de clampare a aortei peste $57 \mathrm{~min}$ determină IRA la $64 \%$ dintre pacienți (12). Transpoziția de vase mari cu defect septal ventricular este încadrată în categoria 4/6 RACHS-1 (Risk Adjustment for Congenital Heart Surgery) (16) și, de 
regulă, se asociază cu timpi operatori prelungiți, aşa cum raportau Wetter și colab., care au găsit timpul mediu de CEC 204 min (120-1554 min) și timpul mediu de clampare a aortei de $115 \mathrm{~min}$ (78-244 $\mathrm{min})$ (17). În cazul pacientei noastre, timpii au fost de 283 min, respectiv $145 \mathrm{~min}$. Există citaţi şi factori de risc postoperatori, precum încărcarea de fluide și necesitatea suportului circulator. Predispoziţia genetică poate fi un factor agravant, identificându-se prezența a două alele (interleukină 6-572C şi angiotensinogen 842C) asociate cu IRA la populația caucaziană după chirurgie aortico-coronariană (18). Deoarece IRA după chirurgia cardiovasculară se asociază cu mortalitate crescută, multe centre inserează cateterul de dializă peritoneală în timpul intervenției sau chiar efectuează dializă peritoneală profilactică $(19,20)$, deși în ultimul timp este preferată hemodiafiltrarea ca metodă de repleție renală după chirurgie cardiovasculară.

Încă de la internare (ziua 4 de viaţă, pacienta a prezentat progresiv edeme cu maximă încărcare de fluide, calculată prin formula ( $\mathrm{G}$ actuală $-\mathrm{G}$ naștere) / G naștere x 100 (3), de 25\% (Figura 1). Piggot și colab. afirmă că încărcarea de fluide mai mare de $30 \%$ se asociază cu mortalitate de $100 \%(11,21)$ și, de aceea, se recomandă ca până la întrunirea criteriilor n-KDIGO să se ia în considerare că mici variaţii în încărcarea de fluide pot fi un semnal de alarmă și să se iniţieze precoce tratamentul diuretic sau CRRT (22).

Redeschiderea sternului sau lăsarea sternului deschis este una dintre opțiunile terapeutice de a scădea compresia cardiacă și de a evita instabilitatea hemodinamică (23). În cazul pacientei noastre, deși după decompresia sternului valorile tensionale au fost în limite normale, nu s-a obținut o creştere a diurezei, iar creatinina a continuat să crească şi edemele s-au accentuat.

Blocul atrioventricular complet, responsabil şi el de instabilitate hemodinamică, este o complicație posibilă în special în formele de transpoziție de vase mari, care asociază şi defect septal ventricular (9). Într-o analiză a Pediatric Cardiac Critical Care Consortium, se apreciază că acesta poate apărea în până la $6 \%$ dintre intervențiile cardiovasculare, iar în 25 $60 \%$ dintre cazuri necesită pacemaker permanent (24). Recomandările curente ale American College of Cardiology, American Heart Association şi Heart Rhythm Society sunt de implantare a stimulatorului definitiv dacă BAV gradul II-III este persistent după 7-10 zile de la intervenția chirurgicală sau ne aşteptăm să fie definitiv $(24,25)$. În cazul pacientei noastre, s-a montat în ziua 18 postoperator.

Chilotoraxul - prin debitul sistemic scăzut, pierderea de proteine și riscul infecțios crescut - este un factor de risc important pentru agravarea IRA. Chilotoraxul apare în 0,5-6,5\% (26) cazuri dintre operațiile cardiovasculare, cu un maximum în ziua 2 postoperator, însă poate apărea până la 29 zile, mai ales daca se insoțește de presiune venoasă crescută (27). Operația de switch arterial a fost cea mai incriminată $(28 \%)$ într-un studiu realizat de Biewer ES și colab., pe 26 pacienți cu chilotorax din 282 intervenții cardiace (26). În apariţia chilotoraxului, cei mai importanţi factori implicați sunt: creșterea presiunii venoase, injuria ductului toracic și formarea unui tromb într-un vas central. Presiunea venoasă crescută (PVC) este un factor foarte important și sunt autori care recomandă profilactic nutriție parenterală totală dacă presiunea venoasă centrală este mai mare $>15 \mathrm{mmHg}$ (28). Există, de asemenea, o corelație strânsă între PVC crescută şi timpii operatori prelungiți (26). La cei mai mulți pacienți cu malformații cardiace congenitale operate, chilotoraxul nu este posttraumatic, ci survine prin anomalii ale fluxului limfatic (29). Ductul toracic este localizat tipic posterior de pericard și este lezat doar atunci când au loc intervenții la nivelul arcului aortic (29). Încărcarea de fluide este, de asemenea, asociată cu cresterea presiunii venoase centrale și cu creșterea presiunii în peretele vascular venos la joncțiunea limfovenoasă $(30,31)$. Tromboza profundă a vaselor este implicată în apariția chilotoraxului, nu doar postoperator, mai ales dacă tromboza se află la nivelul vaselor de pe partea stângă $(30,31)$. Redeschiderea sternului reprezintă un factor de risc suplimentar, susținând ipoteza unor injurii limfatice mediastinale ăi afectarea hemodinamicii postoperatorii.

Chirurgia aortei, creșterea producției de limfă prin iniţierea alimentației, aritmia, care crește presiunea venoasă centrală prin asincronism atrioventricular $(30,32)$, redeschiderea sternului ar putea fi cauze pentru apariția chilotoraxului în cazul pacientei noastre.

În timpul celei de-a doua cure de hemodiafiltrare, fără a exista hemoculturi pozitive, însă cu prezența trombocitopeniei și a markerilor inflamatori crescuți, ne-am orientat și spre coexistența unei infecții care poate avea un rol important în agravarea insuficienței renale. Sepsisul, prin vasodilataţia sistemică mediată citokinic și tulburările de permeabilitate capilară, determină hipoperfuzie renală și necroză tubulară acută ischemică, însă poate cauza și injurie directă, prin mecanisme multiple precum microtrombi vasculari și glomerulari, inflamație şi vasoconstricție (33).

Medicația nefrotoxică administrată (Amikacina, Vancomicina, Furosemid) nu trebuie ignorată și poate avea efect agravant în contextul afecțiunii renale (34). $\mathrm{Nu}$ s-au dozat nivelurile serice ale acestor medicamente, însă s-au administrat doze ajustate pentru IRA. 
În ceea ce privește malfuncționarea stimulatorului cardiac permanent, Kwak și colab., într-un studiu ce a cuprins 48 copii sub un an, dintre care 16 nounăscuți, au găsit că cele mai frecvente incidente sunt: fracturarea, migrarea şi perforarea sondei, disfuncţii ale generatorului, infecțiile, migrarea generatorului sau necroza cutanată (35). La adulți, poate apărea sindrom de injurie postcardiacă după montare de pacemaker (36), care asociază lichid pleural exsudativ de etiologie imună (37), însa foarte rar în populația pediatrică. Nu am găsit raportat în literatură niciun caz de malfuncționare a stimulatorului permanent şi chilotorax, iar asocierea chilotoraxului cu BAV este amintită doar în contextul unor sindroame genetice (38). În cazul pacientei noastre, nu s-a putut stabili cu exactitate natura disfuncției stimulatorului și acesta a fost înlocuit cu unul temporar, cu fire epicardice.

Este rar în Terapia intensivă neonatală ca un pacient să necesite ședințe de hemodiafiltrare repetate și spaţiate în timp in cursul aceleiaşi internări. În clinica noastră, este singurul caz dintre cele 25 hemodiafil-

Conflict of interest: none declared

Financial support: none declared

\section{BIBLIOGRAFIE}

1. Jetton JG, Boohaker LJ, Askenazi DJ; Neonatal Kidney Collaborative (NKC). Incidence and outcomes of neonatal acute kidney injury (AWAKEN): a multicentre, multinational, observational cohort study. Lancet Child Adolesc Health. 2017 Nov;1(3):184-194.

2. Selewski DT, Akcan-Arikan A, Guillet R; Neonatal Kidney Collaborative. The impact of fluid balance on outcomes in critically ill near-term/term neonates: a report from the AWAKEN study group. Pediatr Res. 2019 Jan;85(1):79-85.

3. Askenazi DJ, Stojanović V. Neonatal Critical Care Nephrology. In: Deep A, Goldstein SL. Critical Care Nephrology and renal replacement therapy in children. Springer International Publishing AG 2018:63-71.

4. Kirkley MJ, Boohaker L, Griffin R, Soranno DE, Gien J, Askenazi D, Gist KM; Neonatal Kidney Collaborative (NKC). Correction to: Acute kidney injury in neonatal encephalopathy: an evaluation of the AWAKEN database. Pediatr Nephrol. 2019 Feb;34(2):363.

5. Selewski DT, Charlton JR, Jetton JG, Guillet R, Mhanna MJ, Askenazi DJ, Kent AL. Neonatal Acute Kidney Injury. Pediatrics. 2015 Aug;136(2):e463-73.

6. Owen M, Shevell M, Majnemer A, Limperopoulos C. Abnormal brain structure and function in newborns with complex congenital heart defects before open heart surgery: a review of the evidence. $J$ Child Neurol. 2011 Jun;26(6):743-55.

7. Files MD, Arya B. Preoperative Physiology, Imaging, and Management of Transposition of the Great Arteries. Semin Cardiothorac Vasc Anesth. 2015 Sep;19(3):210-22.

8. Klauwer D, Neuhaeuser C. Renal Aspects of Cardiac Intensive Care In: Klauwer D, Neuhaeuser C, Thoul J, Zimmermann R. A Practical Handbook on Pediatric Cardiac Intensive Care Therapy. Springer International Publishing AG 2019:103-136.

9. Dorfman AL. Transposition of the Great Arteries. In: Alboliras ET, Hijazi ZM, Lopez L, Hagler DJ. Visual Guide to Neonatal Cardiology. John Wiley and Sons Ltd 2018:194-198.

10. Harmer MJ, Southgate G, Smith V. Acute kidney injury and short-term renal support in the post-operative management of neonates following repair of transposition of the great arteries. Progress in Pediatric Cardiology. 2019:(52):26-32. trări efectuate în ultimii 6 ani. De regulă, se așteaptă un al doilea episod IRA la populaţii cu risc, precum prematuri, malformații renale, tromboze de vase renale, enterită ulceronecrotică, chirurgie cardiovasculară multiplă (39).

\section{CONCLUZII}

IRA este una dintre cauzele majore de deces la pacienții cu boală congenitală cardiacă. Asocierea mai multor cauze consecutive, cu etiologie diferită, de injurie renală poate fi fatală la acest grup de pacienţi.

Cazul prezentat este un caz complex, cu factori de risc multipli pentru afectarea renală (suferința fetală acută şi encefalopatia hipoxic-ischemică, malformația cardiacă, prostaglandina, atrioseptostomia, chirurgia cardiovasculară, redeschiderea sternului, blocul atrioventricular complet, chilotoraxul, sepsisul, malfuncționarea stimulatorului cardiac), și care, în ciuda tratamentului maximal suportiv, nu a supraviețuit.
11. Li S, Krawczeski CD, Zappitelli M; TRIBE-AKI Consortium. Incidence, risk factors, and outcomes of acute kidney injury after pediatric cardiac surgery: a prospective multicenter study. Crit Care Med. 2011 Jun;39(6):1493-9.

12. Morgan CJ, Zappitelli M, Robertson CM; Western Canadian Complex Pediatric Therapies Follow-Up Group. Risk factors for and outcomes of acute kidney injury in neonates undergoing complex cardiac surgery. J Pediatr. 2013 Jan;162(1):120-7.e1.

13. Zappitelli M, Bernier PL, Saczkowski RS. A small post-operative rise in serum creatinine predicts acute kidney injury in children undergoing cardiac surgery. Kidney Int. 2009 Oct;76(8):885-92.

14. Cirstoveanu C, Bizubac M, Plesca A. Hemodiafiltration at neonates and small infants: a small retrospective case series. American College of Chest Physicians 2020.

15. Cooper DS, Ricci Z. Post Cardiac Surgery. Acute Kidney Injury and Cardiorenal Syndromes. In: Deep A, Goldstein SL. Critical Care Nephrology and renal replacement therapy in children. Springer International Publishing AG 2018:99-110.

16. Cavalcanti PE, Sá MP, Santos CA. Stratification of complexity in congenital heart surgery: comparative study of the Risk Adjustment for Congenital Heart Surgery (RACHS-1) method, Aristotle basic score and Society of Thoracic Surgeons-European Association for Cardio- Thoracic Surgery (STS-EACTS) mortality score. Rev Bras Cir Cardiovasc. 2015 Mar-Apr;30(2):148-58.

17. Wetter J, Belli E, Sinzobahamvya N. Transposition of the great arteries associated with ventricular septal defect: surgical results and long-term outcome. Eur J Cardiothorac Surg. 2001 Oct;20(4):816-23.

18. Stafford-Smith M, Podgoreanu M, Swaminathan M; Perioperative Genetics and Safety Outcomes Study (PEGASUS) Investigative Team. Association of genetic polymorphisms with risk of renal injury after coronary bypass graft surgery. Am J Kidney Dis. 2005 Mar;45(3):519-30.

19. Webb TN, Basu R, Askenazi D. Diagnosis and Management of Acute Kidney Injury in Critical Illness. In: Mastropietro CW, Valentine KM. Pediatric Critical Care - Current Controversies. Springer Nature Switzerland AG 2019:177-192. 
20. DeSena HC, Nelson DP, Cooper DS. Cardiac intensive care for the neonate and child after cardiac surgery. Curr Opin Cardiol. 2015 Jan;30(1):81-8.

21. Piggott KD, Soni M, Decampli WM. Acute Kidney Injury and Fluid Overload in Neonates Following Surgery for Congenital Heart Disease. World J Pediatr Congenit Heart Surg. 2015 Jul;6(3):401-6.

22. Ueno K, Shiokawa N, Takahashi Y. Kidney Disease: Improving Global Outcomes in neonates with acute kidney injury after cardiac surgery. Clin Exp Nephrol. 2020 Feb;24(2):167-173.

23. Elassal AA, Eldib OS, Dohain AM, Abdelmohsen GA, Abdalla AH, Al-Radi OO. Delayed Sternal Closure in Congenital Heart Surgery: A Risk-Benefit Analysis. Heart Surg Forum. 2019 Aug 27; 22(5):E325-E330.

24. Romer AJ, Tabbutt S, Etheridge SP. Atrioventricular block after congenital heart surgery: Analysis from the Pediatric Cardiac Critical Care Consortium. J Thorac Cardiovasc Surg. 2019 Mar; 157(3):1168-1177.e2.

25. Liberman L, Silver ES, Chai PJ, Anderson BR. Incidence and characteristics of heart block after heart surgery in pediatric patients: A multicenter study. J Thorac Cardiovasc Surg. 2016 Jul; 152(1):197-202.

26. Biewer ES, Zürn C, Arnold R. Chylothorax after surgery on congenital heart disease in newborns and infants -risk factors and efficacy of MCT-diet. J Cardiothorac Surg. 2010 Dec 13;5:127.

27. Czobor NR, Roth G, Prodán Z. Chylothorax after pediatric cardiac surgery complicates short-term but not long-term outcomes-a propensity matched analysis. J Thorac Dis. 2017 Aug; 9(8):2466-2475.

28. Panthongviriyakul C, Bines JE. Post-operative chylothorax in children: an evidence-based management algorithm. J Paediatr Child Health. 2008 Dec;44(12):716-21.

29. Savla JJ, Itkin M, Rossano JW, Dori Y. Post-Operative Chylothorax in Patients With Congenital Heart Disease. J Am Coll Cardiol. 2017 May 16;69(19):2410-2422.
30. Perry T, Bora K, Bakar A, Meyer DB, Sweberg T. Non-surgical Risk Factors for the Development of Chylothorax in Children after Cardiac Surgery-Does Fluid Matter? Pediatr Cardiol. 2020 Jan;41(1):194-200.

31. Ratnayake CBB, Escott ABJ, Phillips ARJ, Windsor JA. The anatomy and physiology of the terminal thoracic duct and ostial valve in health and disease: potential implications for intervention. J Anat. 2018 Jul;233(1):1-14.

32. Chua Chiaco JM, Parikh NI, Fergusson DJ. The jugular venous pressure revisited. Cleve Clin J Med. 2013 Oct;80(10):638-44

33. Schrier RW, Wang W. Acute renal failure and sepsis. N Engl J Med. 2004 Jul 8;351(2):159-69.

34. Hanna MH, Askenazi DJ, Selewski DT. Drug-induced acute kidney injury in neonates. Curr Opin Pediatr. 2016 Apr;28(2):180-7.

35. Kwak JG, Cho S, Kim WH. Surgical Outcomes of Permanent Epicardial Pacing in Neonates and Young Infants Less Than 1 Year of Age. Heart Lung Circ. 2019 Jul;28(7):1127-1133.

36. Kumar S, Madanieh A, Patel H, Srinivasa Murthy R, Goyos JM, Milunski MR. Large Unilateral Pleural Effusion with Pacemakerassociated Post-cardiac Injury Syndrome. Cureus. $2018 \mathrm{Jul}$ 8;10(7):e2946.

37. Lee YJ, Mubasher M, Zainal A, Syed T, Mohamed MFH, Ferrantino M, Hoefen R. Pacemaker-Associated Post-cardiac Injury Syndrome Presenting with Tamponade and Recurrent Pleural Effusion. Clin Med Insights Case Rep. 2020 Oct 30;13:1179547620965559.

38. Fujino S, Maruyama H, Tsukamoto $\mathrm{K}$, Ono H, Isayama T, Ito $\mathrm{Y}$. Chylothorax Associated with Congenital Complete Atrioventricular Block. AJP Rep. 2020 Oct;10(4):e403-e407.

39. Charlton JR, Boohaker L, Askenazi D, Brophy PD, D'Angio C, Fuloria M, Gien J, Griffin R, Hingorani S, Ingraham S, Mian A, Ohls RK, Rastogi S, Rhee CJ, Revenis M, Sarkar S, Smith A, Starr M, Kent AL; Neonatal Kidney Collaborative. Incidence and Risk Factors of Early Onset Neonatal AKI. Clin J Am Soc Nephrol. 2019 Feb 7; 14(2):184-195. 